\title{
De Lasswell a Gorgias: los orígenes de un paradigma
}

\author{
Raquel ForNIELES SÁNCHEZ \\ Universidad Autónoma de Madrid \\ raquel.fornieles@uam.com
}

Recibido: 23 de enero de 2012

Aceptado: 25 de julio de 2012

\begin{abstract}
Resumen
Este trabajo pretende demostrar que la Retórica Clásica es imprescindible para comprender el actual Periodismo. No son muchos los autores que han prestado atención a esta disciplina y, quienes sí lo han hecho, tienden a relacionarla con los géneros periodísticos de opinión. Sin embargo, la Retórica no está ligada solamente a la persuasión y, como pequeña muestra de ello, proponemos un recorrido por esta materia. Partiendo de la aportación de Harold Lasswell y de la fórmula de las 5 W's americanas, nos remontaremos hasta el siglo V a. C. para aproximarnos a las obras que conservamos de un sofista, Gorgias, que merece ser tan tenido en cuenta como el propio Aristóteles.
\end{abstract}

Palabras clave: Retórica Clásica, Periodismo, 5 W's, Gorgias.

\section{From Lasswell to Gorgias: the origins of a paradigm}

\begin{abstract}
This work aims to demonstrate that Classical Rhetoric is essential to understand the current Journalism. Not many authors have paid attention to this discipline and those who have done so tend to relate it to the opinion journalistic genres. However, Rhetoric is not only linked to persuasion and, as a little proof, we propose a walk through this subject. The starting points are the contribution of Harold Lasswell and the 5 W's formula and we go back to the fifth century B. C. in order to approach the works of Gorgias, a sophist who deserves to be so taken into account as Aristotle.
\end{abstract}

Keywords: Classical Rhetoric, Journalism, 5 W's, Gorgias.

Referencia normalizada: FORNIELES SÁNCHEZ, Raquel (2012): "De Lasswell a Gorgias: los orígenes de un paradigma". Estudios sobre el mensaje periodístico, vol. 18, núm. 2 (julio-diciembre), págs.: 739-755. Madrid, Servicio de Publicaciones de la Universidad Complutense.

Sumario: 1. Introducción: Retórica y Periodismo. 2. Punto de partida: la fórmula de las 5 W's. 3. Los estudios y la Retórica Clásica. 4. La Retórica en la primera tesis doctoral de Periodismo. 5. Hermágoras de Temnos. 6. La Retórica Latina: Cicerón y Quintiliano. 7. Aristóteles; 7. 1. Categorías; 7. 2. Tópicos; 7. 3. Ética a Nicómaco; 7. 4. Poética. 8. Los sofistas; 8. 1. Gorgias de Leontinos; 8. 1. 1. El Encomio de Helena; 8. 1. 2. El Defensa de Palamedes. 9. Conclusión. 10. Referencias bibliográficas.

\section{Introducción: Retórica y Periodismo}

No son muchos los estudiosos que han prestado atención a lo importante que es la Retórica Clásica para entender el Periodismo. Además, existe una tendencia generalizada a pensar que la relación entre ambas disciplinas puede establecerse solamente cuando abordamos el análisis de los géneros de opinión ${ }^{1} \mathrm{y}$, sin embargo, no hay nada más lejano a la realidad. Quizá el causante de que esta percepción sea la más extendida haya sido el propio Aristóteles con su definición de la Retórica:

${ }^{1}$ La importante influencia que ejerce la Retórica en los géneros de opinión merece un estudio aparte, mucho más amplio y detenido. Al respecto, véase el excelente trabajo de María Jesús CASAls y Luisa SANTAMARÍA (2000). 


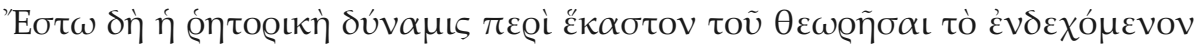
$\pi \iota \theta \alpha$ vóv.

"Definamos la Retórica como la capacidad de teorizar, en cada caso, sobre lo que es capaz de persuadir" (ARISTÓTELES, Retórica 1355b25)².

Esta alusión a la persuasión ${ }^{3}$ nos evoca los editoriales, las columnas, críticas y demás trabajos de opinión, pero es preciso que no obviemos que en este mismo tratado están asentadas, entre otras muchas cosas, las bases del proceso de la comunicación, con independencia de qué género nos ocupe. Basta avanzar unas líneas en el texto aristotélico para leer lo siguiente:

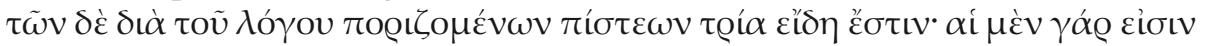

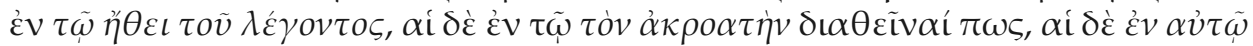

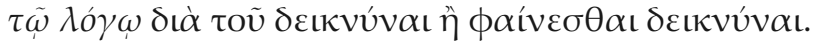

"Hay tres especies de pruebas por persuasión ${ }^{4}$ proporcionadas por el discurso: unas están en el carácter del que habla; otras, en poner al oyente en una determinada disposición; otras, en el propio discurso, por lo que demuestra o parece demostrar" (ARISTÓTELES, Retórica 1356a1).

La presencia de los elementos básicos del acto comunicativo es evidente:

\begin{tabular}{|c|c|}
\hline El emisor (el que habla) & 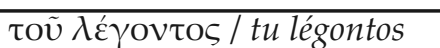 \\
\hline El receptor (el oyente) & 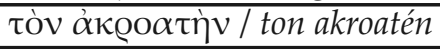 \\
\hline El mensaje (el discurso) & $\tau \tilde{\omega} \lambda{ }^{\prime} \gamma \omega /$ tó $\log O$ \\
\hline
\end{tabular}

Y esto conecta directamente con la estructura externa de la propia obra, pues la Retórica se divide en tres partes: la primera (libro I), centrada en el que habla; la segunda (libro II), en el oyente y la tercera (libro III) en lo que se habla o se escucha, es decir, el mensaje.

Lo que acabo de exponer es solamente una pequeñísima muestra del sinfín de motivos que me llevan a reflexionar sobre la gran consideración que merece Aristóteles

2 Todas las traducciones que aparecen en este artículo son mías. Por otra parte, a lo largo de todo el trabajo presentaré algunos términos en griego que irán acompañados de su correspondiente transliteración (para la que seguiré las normas de acentuación de la ortografía española) y traducción.

3 El término que hace referencia a la persuasión en el texto de Aristóteles es $\pi \imath \theta \alpha v$ óv / pithanón, adjetivo derivado de $\pi \varepsilon \imath \theta \omega ́$ / peithó ("persuasión") que, como veremos, es también un concepto fundamental para comprender a Gorgias. Cf. Nota 24.

4 Estas "pruebas por persuasión" son las $\pi i ́ \sigma \tau \varepsilon ı /$ / pisteis, que pertenecen a la misma familia etimológica que pithanón y peithó. De hecho, entre sus significados están los de "confianza, crédito, garantía" y, de ahí, "prueba". Aristóteles (Retórica, 1355b35) distingue entre prue-

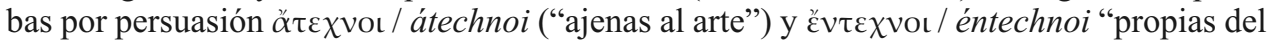
arte". Las ajenas al arte son las que no obtenemos nosotros, sino que existían de antemano, como los testigos o los documentos. Por su parte, las propias del arte son la podemos aportar nosotros mismos. Aplicado al Periodismo, nos encontramos ante las fuentes de información directas e indirectas. 
en los estudios de Periodismo. Y me refiero a Aristóteles porque también es tradición que remitamos a él cuando nos acordamos de la Retórica, pero no es el estagirita el único autor que debemos tener presente. El legado de los clásicos, tanto griegos como

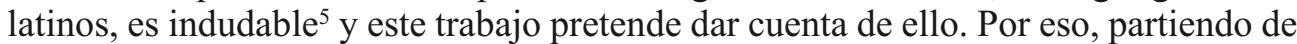
las famosas W's de la prensa informativa, propongo un recorrido por la Retórica Clásica que nos hará remontarnos hasta el siglo $\mathrm{V}$ a. C., concretamente hasta los discursos que conservamos del sofista Gorgias, gran desconocido para muchos y, sin embargo, indispensable para consolidar los cimientos de una disciplina tan reciente como el Periodismo.

\section{Punto de partida: la fórmula de las $\mathbf{5}$ W's}

En 1948, el sociólogo Harold Dwight Lasswell marcó un antes y un después en los estudios de comunicación de masas con la formulación de su famoso modelo, el "Paradigma Lasswell". Afirmaba este estadounidense que "una forma de describir convenientemente un acto de comunicación es la que surge de la respuesta a las siguientes cuestiones: ¿Quién, dice qué, en qué canal, a quién y con qué efectos?" (LASSWELL, 1948: 32-51) ${ }^{6}$. Como bien sabemos, la aplicación de esta regla se hizo imprescindible en la enseñanza del Periodismo, sobre todo a la hora de explicar la estructura interna de la noticia, formada por el lead -en el que se da respuesta a dichas preguntas- y el cuerpo -que amplía la información evidenciando una gradual pérdida del interés en la narración, para lo que se emplea la técnica de la pirámide invertida (MARTínez Albertos, 1992: 296).

También conocemos que la principal contribución de Lasswell estaba en la mención del canal y, especialmente, de los efectos, pero que su propuesta no era tan novedosa. A finales del siglo XIX, Melville Elijah Stone, el primer director de la agencia Associated Press, ya había advertido que la entradilla o lead era la parte más importante de la noticia (SECANELla, 1980: 49). Según Stone, para informar de manera realmente eficaz, el periodista debía aplicar una regla de redacción que consistía en que toda introducción tenía que responder a las siguientes preguntas: quién (Who?), qué (What?), cuándo (When?), dónde (Where?) y por qué (Why?). Más tarde, y debido sobre todo al impulso de los estudiosos españoles, se añadió una sexta cuestión: cómo (How?).

Con el tiempo, la aplicación de la norma de las 5 W's en el lead de los textos informativos se consolidó como el patrón que empleaba todo periodista cuando se disponía a redactar sus noticias. Si el principal objetivo del redactor no era otro que captar la atención del receptor desde el primer momento, qué mejor manera de lograrlo que

5 Demostrarlo es el objetivo de la tesis doctoral en la que trabajo: Iris y Hermes: los géneros periodísticos antes del Periodismo. Un estudio de la Literatura Griega Antigua, dirigida por Emilio Crespo Güemes, catedrático de griego de la Universidad Autónoma de Madrid, y codirigida por María Jesús Casals Carro, catedrática de Periodismo de la Universidad Complutense de Madrid.

${ }^{6}$ El trabajo está traducido en Moragas Spa (1985: 51-68). 
condensando los datos esenciales del acontecimiento noticioso en un breve primer párrafo cuya lectura aporte al lector la esencia del contenido total de la noticia. Ahora bien, ¿es la fórmula de las 5 W's un invento norteamericano? La respuesta es rotunda: no. Como pretende probar este trabajo, los retóricos griegos y latinos ya habían ideado y empleado este recurso muchísimos siglos antes.

\section{Los estudios y la Retórica Clásica}

Ya dijimos al principio de este artículo que gran parte de los estudiosos se han mostrado reticentes a reconocer que muchos de los fundamentos de una disciplina tan moderna como el Periodismo estaban presentes en otra que nos resulta tan lejana en el tiempo. Sin embargo, no sería justo olvidarnos de quienes sí se aproximaron a la Retórica.

Si nos centramos en España, en el curso 1959-60, José Luis Martínez Albertos comenzó a inculcar en el Instituto de Periodismo de la Universidad de Navarra la que, como él mismo señaló, era la primera clasificación de los géneros periodísticos desde un punto de vista filológico. Según MARTínez Albertos (1992: 280), "además de los apartados en que aparecen ordenados los estilos, las actitudes y los géneros -tanto los géneros evidentemente periodísticos como aquellos otros que deben considerarse más bien como propiamente literarios- aparece al final una cuarta columna destinada a los modos de escritura o clases de escritos. Estos modelos nos remiten a las enseñanzas transmitidas a nosotros por la Retórica Clásica: dentro del antiguo 'árbol retórico', la dispositio es la rama en la que coinciden la narración, la descripción, la exposición y la argumentación. Me parece de suma utilidad que los periodistas de nuestra época conozcan los precedentes clásicos de los modos de escritura utilizados hoy para los sofisticados mass-media".

No obstante, el asunto que nos concierne en estos momentos no es la clasificación de los géneros, sino la determinación de los orígenes de las $5 \mathrm{~W}$ 's y, en este sentido, sí se lamentaba Luis NúÑEZ LADÉVEZE (1979:190-191) por el desconocimiento mostrado por la doctrina tradicional respecto al legado de nuestros clásicos: "Los tratadistas del Periodismo han ignorado u olvidado la relación de estos elementos del lead con los desarrollados por la Retórica. Se puede observar la analogía de las preguntas del lead con las Categorías aristotélicas y con funciones gramaticales".

Más interesante aún, si cabe, son las aportaciones de Josep María CASASús (1990: 69-78), que se lamenta de que los estudiosos del Periodismo no sean capaces de ver más allá del siglo XX. Es más, tras asegurar que el Paradigma Lasswell no es de este americano sino de los retóricos latinos, explica que no puede comprender por qué el propio Lasswell, que conocía perfectamente la Retórica Clásica -pues la estudió en Berlín, de la mano de Emil Dovifat, mientras preparaba su doctorado-, la despreció y se apropió de esta fórmula para promocionarla como un descubrimiento norteamericano. Poco después, CASASÚs (1991: 26), atribuía este hecho a que, en su opinión, los periodistas tienden a manifestar lo que él denomina "complejo de Penélope", es decir, el afán por destejer lo que ya estaba tejido, como hacía la fiel esposa de Ulises con el sudario. 


\section{La Retórica en la primera tesis doctoral de Periodismo}

En 1690 se defendió, en Leipzig, la primera tesis doctoral sobre Periodismo: De relationibus novellis ${ }^{7}$. Su autor fue Tobías PEUCER, un erudito que detectó manifestaciones "protoperiodísticas" en textos de la época. Obviamente, cuando este alemán defendió su trabajo el Periodismo era una realidad desconocida que solo comenzaba a asomar. Muchos de los papeles impresos que recogían las novellae ("novedades, noticias") a las que se refería Peucer estaban comenzando a aparecer con cierta periodicidad $^{8}$.

$\mathrm{Al}$ analizar las novellae sobre las que versa su estudio, Tobías Peucer tomaba como referentes a varios autores clásicos. Según él, el modelo ideal se encontraba en el Cómo debe escribirse la Historia de Luciano de Samósata, aunque también prestaba atención a Heródoto, Tucídides, Tácito, Cicerón o Quintiliano. No cita de manera expresa a Aristóteles, pero cuesta creer que no conociera sus tratados. Su dominio de la materia le llevó a hacer la siguiente reflexión sobre la dispositio del relato:

"Por lo que se refiere a la 'economía' y disposición, esta parece depender principalmente de la naturaleza del asunto de que se trata. En efecto, lo que se expone, o son varias cosas de diversa índole, o es solo un asunto individual. En la exposición de aquellas, el orden es arbitrario, ya que no existe nexo alguno entre cosas ocurridas en lugares y tiempos y de modos distintos, y por tanto se mantiene el orden que dicta el azar. Tratándose, en cambio, de un y único asunto debe guardarse en cada caso el orden que le es connatural. Por ejemplo, si alguien quisiera relatar el asedio de Maguncia, iniciado el año pasado, y su subsiguiente conquista, el conjunto debería disponer primero el orden en que cada cosa debe ser descrita. En primer lugar, los autores; luego, la ocasión; después, los preparativos e instrumentos; a continuación, el lugar y el modo de proceder; por último, la acción en sí y sus resultados y el rasgo de valor de los guerreros que más brilló en el asedio y ocupación de la ciudad. Igualmente, si alguien quisiera escribir el relato de la expedición británica emprendida por el príncipe Guillermo de Orange, hoy Rey de Inglaterra, debería tejer su narración siguiendo el mismo orden y manera. En otras narraciones se deben atender de semejante modo las seis conocidas circunstancias que siempre son de esperar en una acción: autor, hechos, causa, modo, lugar y tiempo".

${ }^{7}$ La tesis de PeUCER se publicó por primera vez en España en 1991, en catalán y con el título "Sobre el relats periodístic", en Revista Periodística, no 2. Barcelona, pp. 31-50. La tesis original, en latín, puede consultarse en Estudios sobre el mensaje periodístico, vol. 3, 1996 (monográfico dedicado a la tesis de Tobías PEUCER) pp. 13-35. En este mismo volumen puede consultarse también el texto traducido al castellano y anotado por Ángel SIERRA DE CózAR (profesor de Filología Latina en la Universidad Autónoma de Madrid), pp. 37-52. Madrid, Servicio de Publicaciones de la Universidad Complutense.

${ }^{8}$ En la época de Peucer ya había periódicos (es probable que conociera el primer periódico diario del mundo, el Leipziger Zeitung, que nació en 1660), pero la sociedad aún no tenía conciencia del valor que tenían dichas publicaciones. 
Peucer se refiere a las "seis conocidas circunstancias" "sex illae notae circumstantiae", en el original latino) que esperamos encontrar en toda acción, lo que nos remite a Hermágoras de Temnos, a quien suele atribuirse la paternidad de las "circunstancias", y nos permite iniciar un recorrido por la Retórica Clásica para intentar esclarecer los verdaderos orígenes de las 5 W's.

\section{Hermágoras de Temnos}

Sabemos poco de Hermágoras de Temnos (mediados del siglo II a. C.). Fue el principal representante de la retórica de época helenística y llegó a ser considerado un auténtico reformador de esta disciplina en la línea de Aristóteles y los estoicos. Su obra no ha llegado hasta nosotros, pero conocemos sus aportaciones por la mención que de ella hacen Cicerón y Quintiliano, además de otros retóricos posteriores.

Hermágoras dividió el objeto de la Retórica en dos partes: la tesis ( $\theta \varepsilon ́ \sigma ı /$ thesis),

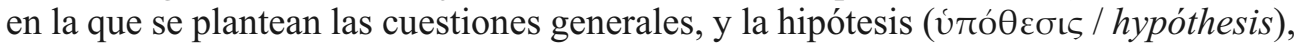
en la que se exponen diversas controversias sobre casos particulares. Como principal diferencia entre ambas, Hermágoras señaló que la hypóthesis se definía mediante siete "circunstancias", según cita San Agustín en su tratado De Rhetorica:

Est igitur circumstantia rerum, quam $\pi \varepsilon \rho i ́ \sigma \tau \alpha \sigma v$ Hermagoras vocat, sine qua ulla omino controversia non potest esse. Quid sit autem peristasis, facilius partitione quam definition eius deprehendi potest. Sunt igitur partes circumstantiae, id est peristaseos, septem, quas Hermagoras $\mu$ ó $1 \alpha \pi \varepsilon \rho 1 \sigma \tau \alpha ́ \sigma \varepsilon \omega \varsigma$ vocat, Theodorus

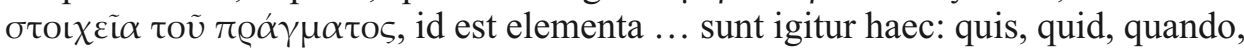

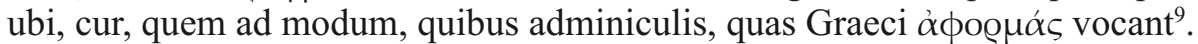

"Es, pues, la circunstancia de las cosas, a la que Hermágoras llama $\pi \varepsilon \rho i ́ \sigma \tau \alpha \sigma ı v^{10}$, sin la cual no puede, en absoluto, existir litigio alguno. Por su parte, qué es una peristasis puede comprenderse más fácilmente por la división que por su definición. Pues son siete las partes de la circunstancia, a las que Hermágoras denomina $\mu$ ópı

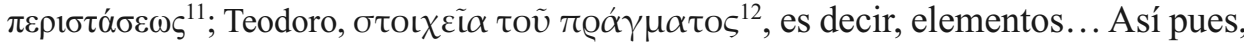
son las siguientes: quién, qué, cuándo, dónde, por qué, de qué modo y con qué medios. Los griegos las llaman $\alpha \dot{\phi o \varrho \mu \alpha ́ \alpha} \varsigma^{13}$ ".

De la línea iniciada por Hermágoras fue continuador, siglos más tarde, Hermóge-

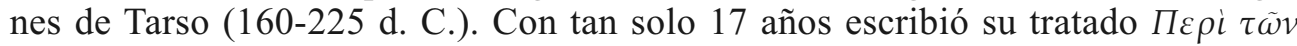

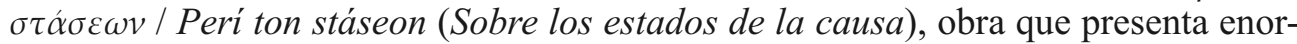
mes paralelismos con la Rhetorica ad Herennium atribuida a Cicerón y la Institutio Oratoria de Quintiliano. En Sobre los estados de la causa, Hermógenes se refiere a

${ }^{9}$ El fragmento está extraído de las páginas 13 y 14 de la edición de MATTHES, Dieter (ed.), Hermagorae temnitae: Testimonia et fragmenta, Teubner, Leipzig, 1962.

10 Acusativo de $\pi \varepsilon p i ́ \sigma \tau \alpha \sigma \iota \varsigma /$ perístasis ("circunstancia").

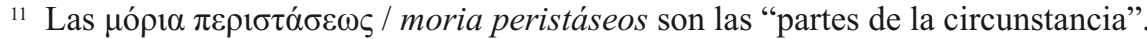

12 "Elementos de la circunstancia". En este contexto, el término $\pi \rho \tilde{a} \gamma \mu \alpha /$ pragma (en principio, "asunto, hecho") se emplea como sinónimo de perístasis.

13 ápopuás / aphormás ("puntos de partida)". 


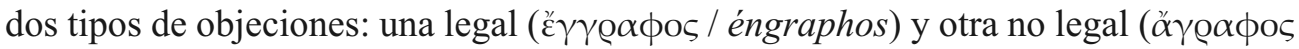
/ ágraphos). Así define Hermógenes la objeción no legal:

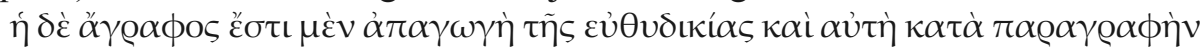

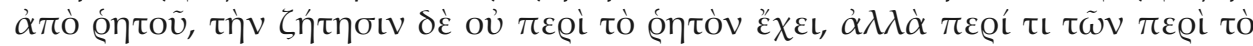

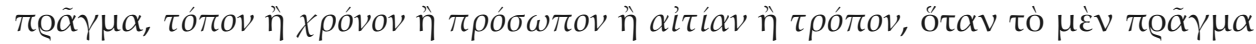

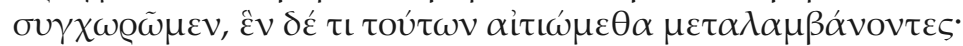

"La no legal es una desviación del juicio directo y ella se produce por excepción sobre lo establecido por la ley, pero la investigación no es sobre la ley, sino sobre las circunstancias del hecho: lugar, tiempo, persona, causa y manera. Se producen cuando estamos de acuerdo en el hecho, pero hacemos la acusación objetando las circunstancias (HeRmóGENES, Sobre los estados de la causa 2, 136".

Como vemos, Hermógenes reduce las siete circunstancias de Hermágoras a cinco,

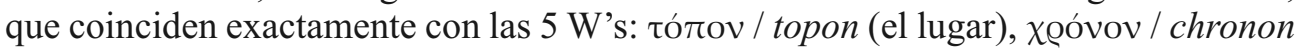

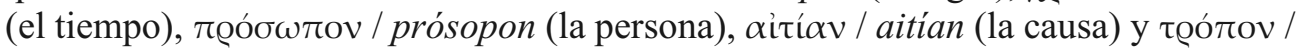
tropon (la manera, el modo).

\section{La Retórica latina: Cicerón y Quintiliano}

Cicerón reproduce en gran medida las teorías de los retóricos de época helenística y buena prueba de ello la encontramos en su obra De inventione (Sobre la invención retórica ${ }^{14}$, donde su ideario depende indisolublemente del pensamiento de Hemágoras. Sin embargo, en determinadas ocasiones muestra estar en desacuerdo con él y le critica duramente. Rechaza, por ejemplo, la división de las causas en generales (thesis) y particulares (hypóthesis ${ }^{15}$. Cuando habla de la argumentación, dice Cicerón que, en ella, toda afirmación es probada por medio de los atributos de las personas y de los atributos de los hechos ${ }^{16}$ y se refiere así a los segundos:

In gestione autem negotii, qui locus secundus erat de iis, quae negotiis adtributa sunt, quaeretur locus, tempus, modus, occasio, facultas.

"Entre las circunstancias de los hechos, que era el segundo punto de los atri-

butos de los hechos, se analizará el lugar, el tiempo, el modo, la ocasión y el medio" (Cicerón, Sobre la invención retórica I 24, 38).

De manera casi idéntica se pronuncia, en el libro V de la Institutio Oratoria, Quintiliano, que a las cinco circunstancias referidas por Cicerón añade una sexta, la causa.

${ }^{14}$ Se trata de la primera obra conservada de Cicerón, un tratado de juventud del arpinate al que la tradición conoce como De inventione o De inventione rhetorica. La idea inicial de Cicerón era componer un ambicioso tratado, pero solamente llegó a escribir dos libros.

15 Cf. Sobre la invención retórica I 6, 8. No obstante, en otras obras Cicerón toma un punto de vista absolutamente contrario. Véase, por ejemplo, De oratore (Sobre el orador) III 27, 106-107 y 120.

${ }^{16}$ Cf. Sobre la invención retórica I 24, 34. Los atributos de las personas son el nombre, la naturaleza, la clase de vida, la condición, la manera de ser, los sentimientos, la afición, la intención, la conducta, los accidentes y las palabras. 
In primus igitur argumenta a persona ducenda sunt; cum sit, ut dixi, divisio, ut omnia in haec duo partiamur, res atque personas, ut causa, tempus, locus, occasio, instrumentum, modus et cetera rerum sint accidentia

"Así pues, los argumentos se deben obtener en primer lugar a partir de la persona, puesto que, como ya he dicho, existe una división para considerar todos los casos en dos apartados: cosas y personas, a las que pertenecen las circunstancias de causa, tiempo, lugar, instrumento, modo y cosas similares (QuINTILIANO, Institutio Oratoria V 10, 23)".

Nunc ad res transeo, in quibus maxime sunt personis iuncta quae agimus, ideoque prima tractanda. In omnibus porro, quae fiunt, quaeritur aut quare? aut $u b i$ ? aut quando? aut quomodo? aut per quae facta sunt?

"Ahora paso al ámbito de las cosas, en las que, principalmente, en el tratamiento que hacemos, encontramos su vinculación con las personas y, por eso, debemos considerarlas en primer lugar. En toda cosa, pues, que se hace, lo que se pregunta es: ¿por qué se hizo?, ¿dónde?, ¿cuándo?, ¿de qué modo? ¿con qué medios? ${ }^{17}$ (QuINTILIANO, Institutio Oratoria V 10, 32)".

\section{Aristóteles}

Es inevitable que volvamos a Aristóteles y casi también lo es que pensemos en su Retórica. Sin embargo, ante una obra tan prolífica como la del estagirita, no sería del todo acertado centrar todo el interés en una parte tan pequeña. En la búsqueda del origen de la fórmula de las 5 W's el abanico de posibilidades se amplía muy considerablemente y, curiosamente, no debemos buscar en la Retórica, pues no será allí donde las encontremos. Veamos dónde debemos hacerlo.

\section{1. Categorías ${ }^{18}$}

Categorías es un breve tratado incompleto que forma parte del Órganon ${ }^{19}$ aristotélico y que describe (pero no define) las categorías. Así se refiere a ellas el estagirita antes de analizarlas:

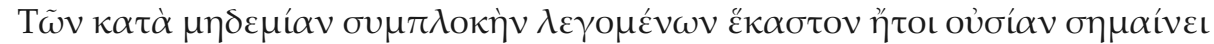

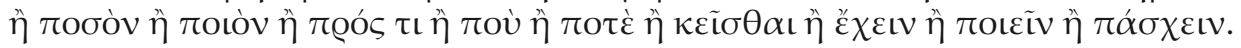

"Cada una de las cosas que se dicen sin ninguna combinación significa una entidad, o un cuánto, o un cuál, o un respecto a qué, o un dónde, o un cuándo, o un estar situado, o un estar, o un tener o un padecer (ARISTÓTELES, Categorías, 1b25)".

\section{2. Tópicos}

Esta obra debe ser entendida dentro de un contexto social muy concreto. Existía en la Atenas clásica una costumbre centrada en la celebración de debates públicos en la que dos litigantes, profesionales o, simplemente, aficionados, discutían sobre un jui-

${ }^{17}$ Literalmente: “¿por medio de qué?”.

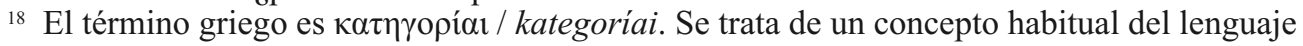
judicial cuyo sentido original es "acusación".

19 Órganon es el nombre genérico que designa las obras de lógica de Aristóteles: Categorías, Sobre la interpretación, Analíticos primeros, Analíticos segundos, Tópicos y Sobre las refutaciones sofisticas. 
cio establecido de antemano. Uno de los personajes asumía el papel de defensor de una tesis y su adversario hacía las veces de refutador, para lo cual realizaba una serie de preguntas lo más insidiosas posible. Para construir sus razonamientos, el que lanzaba las cuestiones se servía de los "lugares" ( Llamaremos aquí la atención sobre esta afirmación de Aristóteles:

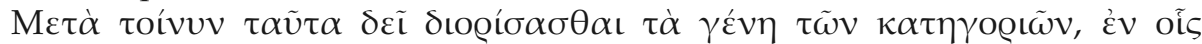

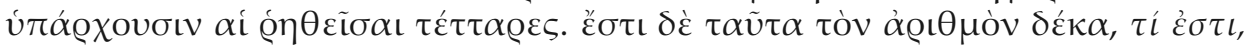

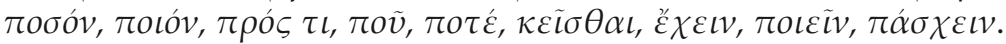

"Después de esto, debemos delimitar las clases de categorías en las que se dan las cuatro cosas que han sido mencionadas. Estas son, en cuanto a número, diez: qué es, cuánto, cuál, respecto a algo, dónde, en algún momento, hallarse situado, estar, hacer, padecer. (ARISTÓTELES, Tópicos I 103 b.20)".

\section{3. Ética a Nicómaco}

Michael C. SLOAN (2010: 236) ha defendido recientemente que el esquema de las siete circunstancias adoptado por los retóricos clásicos posteriores, por los comentaristas medievales y todavía en la actualidad por los periodistas en lo que él denomina "importantísimas 5 W's (y una $\mathrm{H}$ ) del Periodismo" no es una invención de Hermágoras de Temnos, sino de Aristóteles y nos remite al siguiente pasaje de la Ética a Nicómaco:

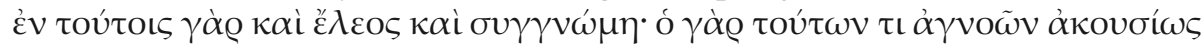

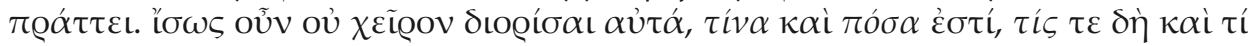

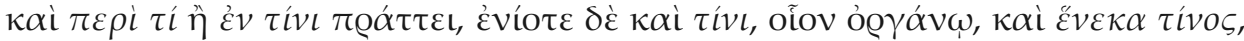

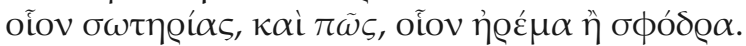

"Pues en ellas ${ }^{20}$ se encuentran tanto la compasión como el perdón, pues el que no conoce alguna de ellas actúa involuntariamente. Por lo tanto, quizá no estaría mal delimitarlas: cuáles y cuántas son, quién actúa y qué hace y acerca de qué o en qué actúa y, a veces, también con qué, por ejemplo, con qué instrumento; y por qué causa, por ejemplo, por causa de la salvación; y cómo actúa: por ejemplo, si actúa de manera tranquila o violentamente (ARISTÓTELES, Ética a Nicómaco 1111b3-5)".

\section{4. Poética}

La Poética es una obra muy breve e incompleta que apenas se ha tenido cuenta en los estudios de Periodismo y que, sin embargo, está repleta de sorpresas. En mi opinión, este tratado sobre la composición es casi tan importante como la Retórica aristotélica y podríamos considerar ambos trabajos como auténticos libros de estilo para periodistas $^{21}$. También podemos rastrear unos perfectos antecedentes de las 5 W's en la Poética:

20 Este ellas hace referencia a "las circunstancias concretas y al objeto de la acción". Anteriormente, Aristóteles estaba diferenciando entre actos voluntarios e involuntarios y señalaba que el término "involuntario" no se emplea cuando alguien desconoce lo que es conveniente, sino cuando ignora las circunstancias y el objeto de la acción.

${ }^{21}$ Defendí esta idea en el I Encuentro de Jóvenes Investigadores en Filología Clásica, celebrado en la Universidad Autónoma de Madrid los días 27 y 28 de noviembre de 2011 con una comunicación titulada La Retórica y la Poética de Aristóteles: libros de estilo para periodistas. 


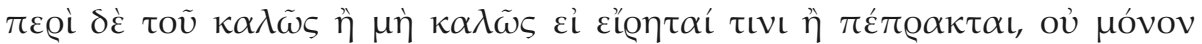

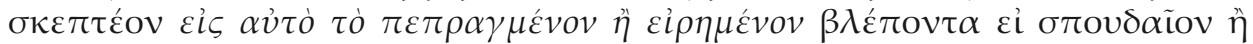

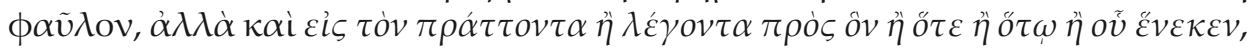

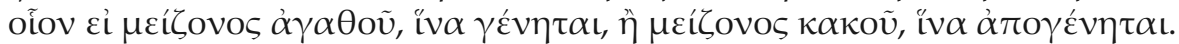

"Acerca de si un personaje ha dicho o hecho algo bien o mal, no debe centrarse la atención solamente en lo que ha hecho o dicho en sí mismo, atendiendo a si es honrado o mezquino, sino también al que actúa o habla, a quién se dirige, cuándo, cómo y con qué fin; por ejemplo, si es para lograr un bien mayor o para evitar un mal mayor (Aristóteles, Poética, 1461a4)".

\section{Los sofistas}

Situémonos en la época de Pericles (mediados del siglo V a. C.), momento cumbre de la democracia y periodo de máximo esplendor de una Atenas que se había consagrado como la gran capital cultural del mundo griego. Por citar algunos ejemplos, fue por aquel entonces cuando Sófocles y Eurípides compusieron sus tragedias y Aristófanes hizo lo propio con sus comedias. También en esos años desarrollaron su actividad intelectuales como Anaxágoras, Sócrates o Platón. Numerosos personajes relevantes de todos los ámbitos acudieron a Atenas atraídos por su magnificencia, entre ellos, los sofistas. Hombres como Protágoras de Abdera, Pródico de Ceos, Gorgias de Leontinos, Hipias de Élide, Trasímaco o Antifón, desempeñaron un papel importante en la vida cultural del momento.

Deseados y odiados, respetados y criticados, entre otras cosas se les acusó de in-

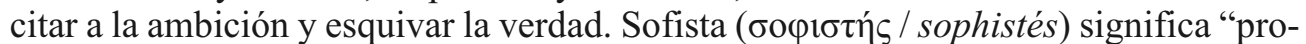
fesional de la sabiduría" y conviene diferenciarlo del filósofo (

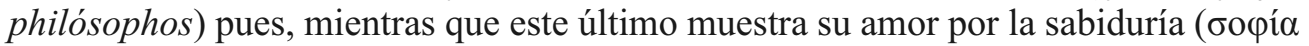
/ sophía), el sofista la utiliza como profesión, se beneficia de ella y cobra por hacerlo. El término no implica connotaciones negativas, pero lo cierto es que los sofistas fueron muy criticados y su nombre adquirió con el tiempo tintes despectivos. Gran parte de culpa la tiene la presentación que de ellos nos hace Platón en sus diálogos, donde aparecen con frecuencia como interlocutores de un Sócrates que los ridiculiza dejándoles en evidencia constantemente.

La helenista Jacqueline de Romilly defendió a ultranza a los sofistas y así se refería a ellos: "No eran sabios, sino especialistas en sabiduría, profesionales de la inteligencia, maestros del pensamiento y de la palabra". Maestros, sobre todo eso, maestros. Por eso hace hincapié Romilly (1998: 237) en su apasionada apología, porque "fueron los primeros en impartir, con vistas a una vida práctica, una enseñanza intelectual como la que todavía se imparte en la actualidad".

\section{1. Gorgias de Leontinos}

Gorgias nació en Sicilia, en Leontinos (actual Lentini) en el 485 a. C. Las fuentes destacan su longevidad pues, según parece, murió a los 109 años. Viajó a diversos lugares durante gran parte de su vida y en el 427 a. C. llegó a Atenas como embajador de su patria para solicitar a los atenienses su apoyo en la guerra contra Siracusa e, inmediatamente, cautivó a todos con sus discursos. Los juegos de palabras y la riqueza de 
figuras estilísticas de las que se servía, que hacen que su estilo nos resulte algo tedioso hoy día, no dejaron indiferente a nadie en aquel entonces.

Desde mi punto de vista, Gorgias es el gran desconocido de los estudiosos de la comunicación ${ }^{22} \mathrm{y}$, sin embargo, una figura absolutamente necesaria. Paso a exponer a continuación algunos pasajes que me ayudarán a demostrarlo.

Sabemos por Sexto Empírico que Gorgias compuso un tratado llamado Sobre el no ser o Sobre la naturaleza donde sostiene lo siguiente:

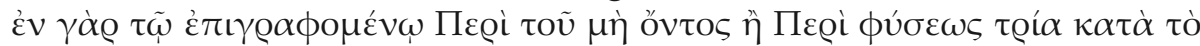

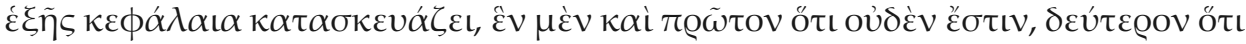

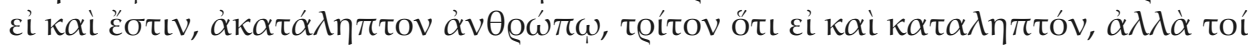

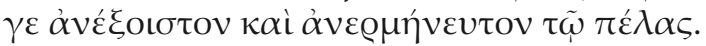

"En efecto, en su obra titulada Sobre el no ser o Sobre la naturaleza, dispone tres argumentos sucesivos. El primero, que nada existe; el segundo, que, incluso si algo existe, es incomprensible para el hombre; y el tercero, que, incluso si algo fuera comprensible, no puede ser comunicado ni explicado a otros" (SEXTO EMPÍRICO, Contra los Matemáticos VII 65-ss.).

\section{1. 1. El Encomio de Helena}

El discurso más conocido de Gorgias es, sin duda alguna, el Encomio de Helena ${ }^{23}$, en el que despliega su doctrina del $\lambda$ ó $\gamma$ os / logos:

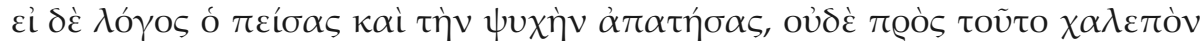

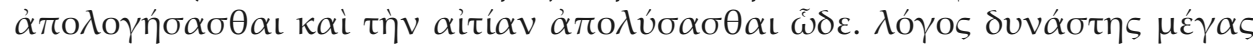

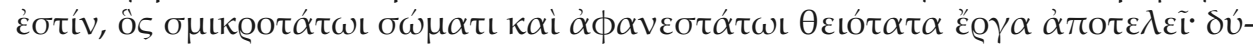

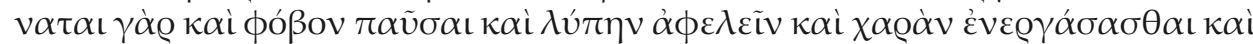

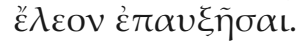

"Si fue la palabra la que la persuadió y engañó su mente, no es difícil tampoco defenderla y liberarla de la acusación de la siguiente manera. La palabra es un poderoso soberano que, con un cuerpo pequeñísimo y totalmente invisible, lleva a cabo obras absolutamente divinas. Puede, por ejemplo, acabar con el miedo, anular la aflicción, producir alegría o acrecentar la compasión (Gorgias, Encomio de Helena, 8)".

Hay varios conceptos clave en este texto. Uno de ellos es la persuasión ${ }^{24}(\pi \varepsilon \iota \theta \omega /$ peithó) pues, por medio de ella, la palabra (el logos) puede inducir al oyente a un en-

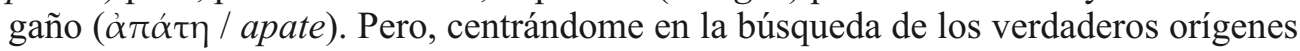
de las 5 W's, quiero llamar la atención sobre otro fragmento. Previamente, antes de adentrarse de lleno en la defensa de Helena, Gorgias nos presenta - como es habitual

${ }^{22}$ Debo destacar la atención que sí ha prestado María Jesús CASAls (2011: 45-67) al Encomio de Helena.

${ }^{23}$ Helena de Troya, esposa de Menelao, rey de Esparta, que abandonó a su marido para marcharse con Paris. Su fuga provocó la Guerra de Troya.

${ }^{24}$ Cf. Nota 3 para ver la importancia de este término y de su familia etimológica en Aristóteles. 
en sus discursos, basados en un método apagógico ${ }^{25}$-, las motivaciones por las que podría haberse dejado llevar la esposa de Menelao: la fortuna ( $\tau u ́ \chi \eta / t u k h e$ ), la vio-

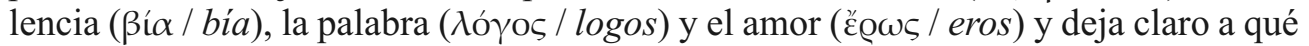
no tiene previsto hacer referencia. En este contexto, ya intuímos aquí un pequeño atisbo de las cuestiones del Periodismo:

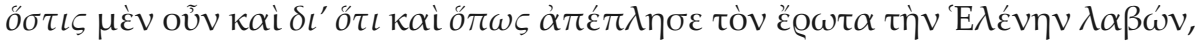

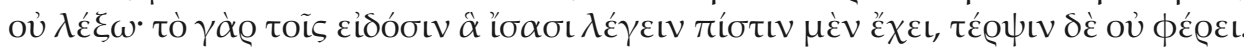

"Pues bien, quién y por qué causa y de qué modo colmó su amor tomando a Helena, no voy a decirlo. Porque decir a aquellos que saben lo que saben concede crédito, pero no procura placer (GoRGIAs, Encomio de Helena, 5)".

No obstante, Gorgias nos regala otro pasaje mucho más interesante desde este punto de vista y no se encuentra precisamente en el Encomio de Helena, sino en otro de los discursos que han llegado hasta nosotros, el Defensa de Palamedes.

\section{1. 2. El Defensa de Palamedes}

Palamedes es el paradigma de héroe cultural -pues a él se atribuía la invención del alfabeto, de los números, el uso de la moneda, el cálculo de la duración de los meses según el curso de los astros y algunos juegos, como los dados o las damas- y representa el prototipo de hombre que ha sido acusado de manera injusta.

Sus rencillas con Ulises comenzaron cuando este último fingió haberse vuelto loco para no verse obligado a luchar en la Guerra de Troya. Palamedes descubrió su engaño y Ulises, en venganza, urdió una auténtica conspiración contra él: falsificó una carta de Príamo - rey de Troya- destinada a Palamedes en la que este quedaba retratado como traidor de los griegos. Además, para dar mayor credibilidad al asunto, enterró una considerable cantidad de dinero bajo su tienda. Cuando los griegos descubrieron ambas cosas, Palamedes fue condenado a muerte y ejecutado.

Aunque el Encomio a Helena y el Defensa de Palamedes tienen como objetivo común defender a dos figuras maltratadas por la tradición griega se aprecian notables diferencias de estilo entre ellos. Una pista la encontramos en sus títulos. El discurso dedicado a la esposa de Menelao es un elogio, un encomio ( $\gamma \kappa \omega ́ \mu 10 v /$ encomion ) y el propio Gorgias deja claras sus intenciones, pues cierra su disertación con este broche:

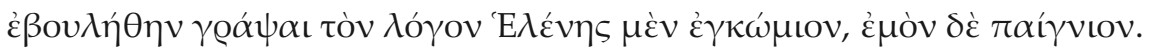

"Quise escribir este discurso como un encomio de Helena y como un juego de mi arte (Gorgias, Encomio de Helena, 21)”.

Es Gorgias quien alaba a Helena para liberarla de la gran cantidad de infamias vertidas contra ella. La esposa de Menelao no toma la palabra en ningún momento. En cambio, el Defensa de Palamedes no es una loa sino precisamente eso, una defensa,

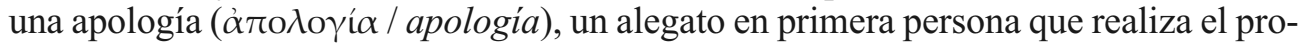

25 El método apagógico consiste en proponer dos posibilidades y, una vez que se ha demostrado la falsedad de una de ellas, su contraria es, necesariamente, verdadera. 
pio héroe consciente de que es el único recurso que le queda para intentar demostrar su inocencia.

Pongámonos en situación. El discurso había comenzado con un proemio (1-5) introductorio en el que Palamedes no necesita remitirse a los hechos por los que ha sido acusado, pues entiende que son suficientemente conocidos por todos, pero sí expresa la que será la base de su defensa:

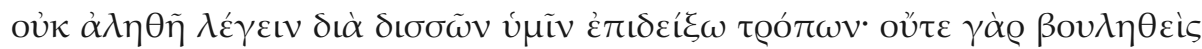

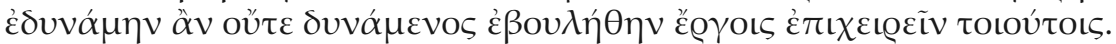

"Os mostraré que no dice la verdad por medio de dos argumentos: ni si hubiese querido, habría podido ni, si hubiese podido, habría querido emprender tales acciones (Gorgias, Defensa de Palamedes, 5)".

Inmediatamente después comienza la segunda parte del discurso, que tiene como principal objetivo la demostración de la tesis (6-21) y, una vez que Palamedes ha ex-

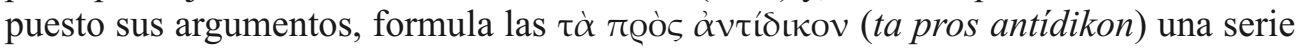
de preguntas dirigidas directamente al oponente (22-26):

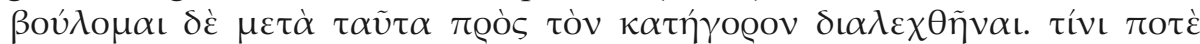

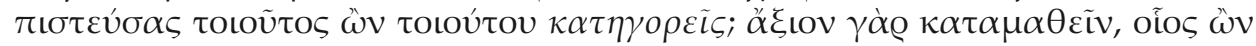

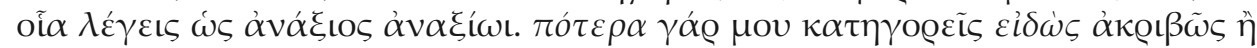

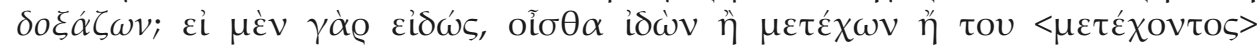

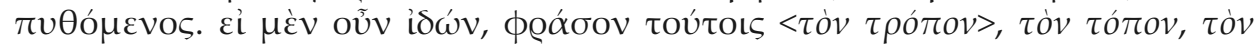

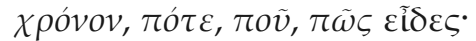

"Y, después de estos argumentos, quiero discutir con mi acusador. ¿Creyendo en qué acusas un hombre como tú a otro como yo? Realmente, merece la pena estar completamente informado de qué clase de hombre eres y qué clase de acusaciones haces. ¿Qué inmerecido para quien no las merece! ¿Acaso, pues, me acusas porque conoces los hechos con exactitud o porque lo sospechas? Pues si es porque los conoces, lo sabes porque los has visto o porque has participado o porque te has informado por alguien que participó. Por tanto, si los viste, revela a estos el modo, el lugar, el tiempo, cuándo, dónde, cómo viste" (Gorgias, Defensa de Palamedes, 22).

En este caso, las cuestiones se enuncian como un simple recurso retórico, ya que Palamedes no va a obtener respuesta alguna. El héroe no necesita preguntar abiertamente por el quién ni por el qué: el quién es Ulises, al que se está dirigiendo en ese momento, y el qué es la acusación de traición, motivo por el cual se encuentra en esta desagradable coyuntura. Sin embargo, ambas cuestiones están recogidas de forma im-

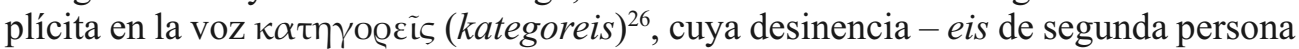
del singular despeja cualquier duda y su propio significado ("acusar") nos indica que el asunto principal no es otro que la acusación vertida contra él.

26 Un momento antes ha manifestado Palamedes que quiere discutir con su acusador

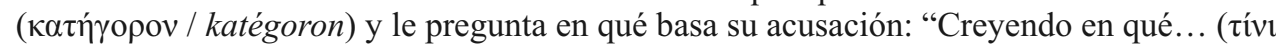
$\pi ı \tau \varepsilon v ́ \sigma \alpha \varsigma$ / tíni pisteusas)". 
Sí está expreso, en cambio, el interrogante de la causa por medio del interrogativo

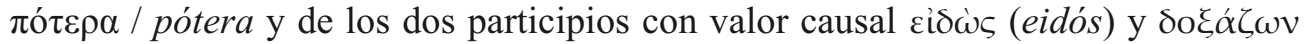
(doxáxon). Pero lo más importante se concentra al final del pasaje, en el momento en que Palamedes pide pruebas contundentes a Ulises:

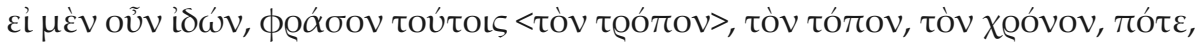
$\pi \mathrm{ov}, \pi \tilde{\omega} \varsigma \varepsilon \tilde{\imath} \delta \varepsilon \varsigma^{\circ}$

"Si los viste, dales a conocer a estos:

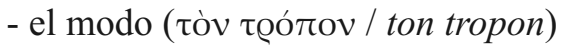

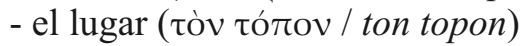

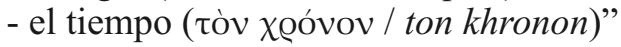

O lo que es lo mismo:

- "cuándo ( $\pi$ tó / pote)

- dónde $(\pi \circ \tilde{v} / p u)$

- cómo $(\pi \tilde{\omega} \varsigma /$ pos $) "$

Si comparamos todo esto con la fórmula de las W's el resultado es el siguiente:

\begin{tabular}{|c|c|}
\hline ¿Quién? & 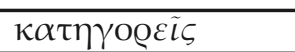 \\
\hline ¿Qué? & 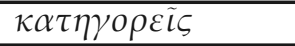 \\
\hline ¿Cuándo? & 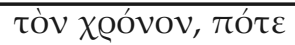 \\
\hline ¿Dónde? & 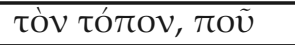 \\
\hline ¿Por qué? & 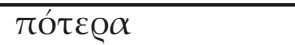 \\
\hline ¿Cómo? & 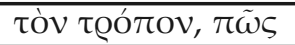 \\
\hline
\end{tabular}

Pero no son las interrogantes el único motivo por el que considero este pasaje de especial relevancia. Prestemos atención ahora al texto que precede a estas preguntas:

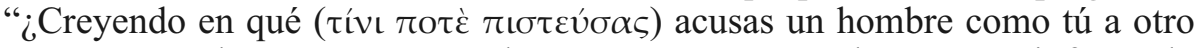
como yo? Realmente, merece la pena estar completamente informado ( $\kappa \tau \tau \alpha \mu \alpha \theta \varepsilon i v)$ de qué clase de hombre eres y qué clase de acusaciones haces. ¡Qué indigno para quien no las merece! ¿Acaso, pues, me acusas porque conoces los

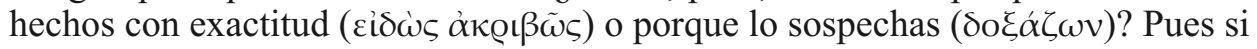

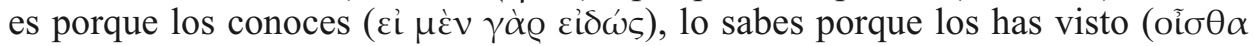

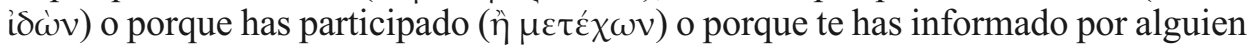

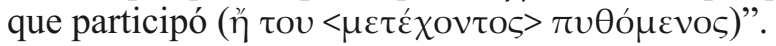

Como diría Aristóteles, la alusión a las fuentes de información (imprescindibles, como bien sabemos, para todo periodista) "salta a la vista" ${ }^{27}$. Palamedes asegura que

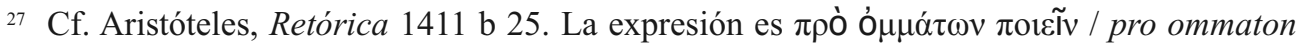
poiein. Literalmente quiere decir: "Poner ante los ojos" y suele traducirse como "saltar a la vista". Según explica Aristóteles, a lo que se refiere con esta locución es a que la expresión se aplique a hacer sensible el contenido del mensaje. En Poética 1455 a 25 varía el verbo

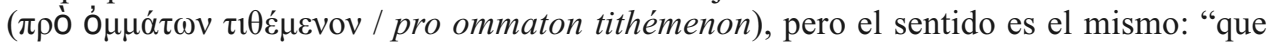
quede expuesto ante los ojos". 
quiere enterarse exactamente ${ }^{28}$ de por qué puede Ulises acusarle con tanta seguridad, de dónde proceden los datos que le han permitido llevarle a ser juzgado.

Las clasificaciones de las fuentes de información atienden a diversos criterios y uno de ellos, el que más nos interesa en este momento, es el que considera la relación que se mantiene con el hecho noticioso, con el objeto de conocimiento. En este sentido, se distingue entre fuentes primarias (las que están informadas por que han participado directamente en el acontecimiento o pueden contarlo porque han sido testigos oculares - en un auténtico ejercicio de aùtớ́a / autopsía o acción de ver algo con los propios $\operatorname{ojos}^{29}$ ) y fuentes secundarias (fuentes de segunda mano, que transmiten lo que otros les han comunicado a ellas). Esto es, precisamente, lo que tenemos aquí.

En primer lugar, Palamedes plantea una duda: ¿el conocimiento que tiene Ulises de lo sucedido es exacto o, por el contrario, una simple sospecha? ${ }^{30}$ Si ocurriera esto último, su acusación carecería de validez. Ahora bien, si lo que llevó a Ulises a denunciarle no fue una simple suposición sino una creencia a ciencia cierta, tiene que haberse producido de una de estas dos maneras: bien porque Ulises vio personalmente lo sucedido o tomó parte en los hechos (lo que le convertiría en fuente primaria), bien porque otra persona que fue testigo directo se lo ha contado (en cuyo caso, el esposo de Penélope sería una fuente secundaria).

\section{Conclusión}

Siempre he pensado que muchas de las bases teóricas del Periodismo ya estaban asentadas en la Retórica Clásica y con este trabajo pretendo llamar la atención sobre ello. Todos los que nos hemos dedicado al Periodismo conocemos la técnica de la pirámide invertida y recitamos de memoria la fórmula de las 5 W's. Por supuesto, todos hemos oído también hablar del Paradigma Lasswell. Y yo me pregunto lo siguiente: ¿por qué hablamos de Paradigma Lasswell y no reconocemos el mérito a Aristóteles $\mathrm{o}$ a Gorgias? Como hemos comprobado, hay numerosos modelos similares en la Retórica Clásica y considero que merece la pena destacar la relevancia que tienen los trabajos de estos autores para comprender algunos de los principios de una disciplina

28 Es importante llamar la atención sobre el $\kappa \alpha \tau \alpha \mu \alpha \theta \varepsilon \tilde{I}$ / katamathein del texto griego. En contraste con la duda que se plantea a continuación, Gorgias pone en boca de Palamedes el

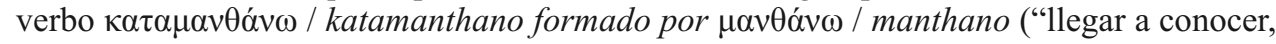
informarse") y el preverbio $\kappa \alpha \tau \alpha$ - katá ("de arriba abajo"), que aporta la idea de totalidad. Hay que contraponerlo con el $\pi v \theta$ ó $\mu \varepsilon v o \varsigma$ / pythómenos ("informarse") del final.

29 La autopsía es importante ya desde Homero. Expresiones como "lo he visto con mis propios ojos" se repiten hasta la saciedad tanto en la Ilíada como en la Odisea. Véase en la nota 4 el tratamiento de las fuentes que hace Aristóteles.

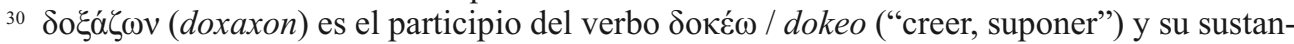

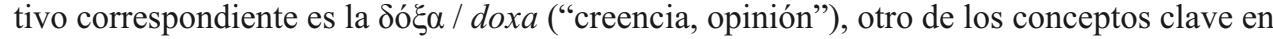
la doctrina gorgiana, pues nos lleva a la oposición entre creencia y verdad y a los argumentos de verosimilitud, los غ́oı́ó $\alpha$ / eoikota, cuyo hallazgo se atribuye a Tisias y al propio Gorgias. María Jesús CASALS (2011: 47-50) llama la atención sobre la importancia del concepto "verosímil" (eikós) aplicado al Periodismo. 
tan reciente como el Periodismo. Obviamente, ni Gorgias ni Aristóteles ni ninguno de los autores a los que he hecho referencia pensaban en términos periodísticos, pero debemos tener en cuenta sus aportaciones porque, entre otras cosas, cuando lo hacemos es fácil advertir que aún discurrimos como ellos en muchos sentidos. Por eso, creo que no podemos olvidarnos de nuestros clásicos.

\section{Referencias bibliográficas}

CASALS, María Jesús (2011): "El universo retórico del Periodismo", en SÁNCHEZ CALERO, María Luisa (ed.): Géneros y discurso periodístico. Madrid, Fragua, pp. 47-73.

CASALS, María Jesús y SANTAMARÍA, Luisa (2000): La opinión periodística. Argumentos y géneros para la persuasión. Madrid, Fragua.

CASASÚS, Josep Maria (1990): "Per una harmonització de les teories esdevenimentals dins la periodística". Revista Periodística, n 2. Barcelona, pp. 69-78.

CASASÚS, Josep Maria (1991): Iniciación a la periodística: manual de comunicación escrita y redacción periodística informativa. Barcelona, Teide.

CASASÚS, Josep Maria y NÚÑEZ LADEVEZE, Luis (1991): Estilo y géneros periodísticos, Barcelona, Ariel.

LASSWELL, Harold (1948): "The Structure and Function of Communication in Society", en BRYSON, L. (comp.): The Communication of Ideas. New York, Harper, pp. 32-51.

MARTÍNEZ ALBERTOS, José Luis (1992): Curso general de redacción periodística. Madrid, Paraninfo.

MARTÍNEZ SOLANA, María Yolanda (2011): "La noticia, género periodístico por excelencia", en SÁNCHEZ CALERO, María Luisa (ed.), Géneros y discurso periodístico. Madrid, Fragua, pp. 133-15

MATTHES, Dieter (ed., 1962): Hermagorae temnitae: Testimonia et fragmenta. Leipzig, Teubner.

MORAGAS SPA, M. (1985): Sociología de la comunicación de masas, volumen II (Estructura, funciones y efectos). Barcelona, Gustavo Gili, pp. 51-68.

NúÑEZ LADEVEZE, Luis (1979): El lenguaje de los media. Madrid, Pirámide.

PEUCER, Tobías [Leipzig, 1690] (1996): "De Relationibus Novellis". Estudios sobre el mensaje periodístico, vol. 3, 1996 (monográfico dedicado a la tesis de Tobías Peucer), pp. 13-35 (texto latino original) y pp. pp. 37-52 en su versión en castellano (traducido y anotado por Ángel Sierra de Cózar). Madrid, Servicio de Publicaciones de la Universidad Complutense.

ROMILLY, Jacqueline de (1997): Los grandes sofistas en la Atenas de Pericles. Barcelona, Seix Barral.

SECANELLA, Petra M. (1980): El lid, fórmula inicial de la noticia. Barcelona, A.T.E. 
SIERRA DE CÓZAR, Ángel (1996): “Traducción castellana y notas del texto latino de la tesis de Tobías Peucer", en Revista Estudios sobre el mensaje periodístico, $\mathrm{n}^{\circ}$ 3. Madrid: Servicio de Publicaciones UCM, pp. 39-52.

SLOAN, MICHAEL C. (2010): “Aristotle's Nicomachean Ethics as the original Locus for de Septem Circumstantiae", en Revista Classical Philology, no 3. Chicago, pp. 236-251. 